\title{
A integração latino-americana no século XIX: antecedentes históricos do Mercosul
}

\author{
Ricardo Soares Stersi dos Santos*
}

Sumário: Introdução; 1. O pensamento de Simón Bolívar; 2. O Congresso do Panamá; 3. Os congressos posteriores; 4 . O panamericanismo. Conclusão. Referências.

\begin{abstract}
Resumo: Hoje, quando se pensa em integração latino-americana, imediatamente se associa a imagem das organizações internacionais regionais existentes: Mercosul, Pacto Andino, Mercado Comum Centro-Americano. Ocorre que a história da integração latino-americana é muito anterior a essas organizações internacionais e nasce em conjunto com o próprio ideal de independência dos Estados latino-americanos, em pleno século XIX. Como se verá na pesquisa, as idéias integracionistas iniciaram com a busca da união política entre os Estados latino-americanos e só mais adiante adotaram as perspectivas econômicas que atualmente as definem.
\end{abstract}

Palavras-chave: Integração; Cooperação; Confederação; Panamericanismo.
Abstract: Today, when one thinks about integration in Latin-American, immediately associated with the image of existing regional international organizations: Mercosur, Andean Pact, Central American Common Market. What happens is that the history of Latin-American integration is prior to those international organizations and born together with the ideal of independence the Latin-Americans countries, in 19 th century. As seen in research, the ideas integrationists started with the search for political union between the countries of Latin-Americans and, only later, adopted economic prospects that currently defined.

Keywords: Integration; Cooperation; Confederation; Pan-Americanism.

\section{Introdução}

As idéias de integração econômica, política e social dos países da América Latina foram defendidas por diversos pensadores ${ }^{1}$ antes mesmo que esses Estados tivessem conquistado sua independência em relação às metrópoles européias: Espanha, França, Inglaterra e Portugal.

\footnotetext{
* Mestre e Doutor em Direito pela Universidade Federal de Santa Catarina (UFSC). Professor dos Cursos de Graduação e de Pós-Graduação em Direito (Mestrado e Doutorado) da UFSC. Professor Visitante da Faculdade de Direito da Universidade de Buenos Aires.

${ }^{1}$ Entre outros se pode citar: o padre Alexandre de Gusmão, Pablo Olavide, Francisco de Miranda, Andrés Bello, Bernardo O’Higgins, Juan Alberdí, San Martín e Simón Bolívar.
} 
O pensamento desenvolvido por esses visionários ia desde o fortalecimento bélico para enfrentar as antigas metrópoles até a necessidade de robustecimento dos laços políticos e econômicos necessários para alavancar o desenvolvimento dos países sul-americanos em comparação aos países europeus.

A própria idéia de integração, entretanto, é por demais abstrata para se criar um conceito que seja aceito por todos. Azevedo define a integração em sentido amplo como sendo o "acordo de vontades entre unidades nacionais, para chegar a uma solução uniforme em determinados campos onde a atividade estatal isolada torna-se inoperante ou ineficiente". ${ }^{2}$ Para tanto é possível a existência de integração política, econômica, militar, social, cultural, jurídica etc.

A integração pressupõe a criação de centros de decisões comunitários que possuem competências atribuídas pelos Estados-membros e deles subtraídas. $\mathrm{Na}$ integração, o processo é voltado para a satisfação dos interesses comunitários. Difere da cooperação internacional, que não apresenta maiores limitações aos poderes estatais, permitindo que cada Estado possa alcançar, no processo de cooperação, a satisfação dos interesses individuais.

Segundo o Instituto Interamericano de Estudos Jurídicos Internacionais, a cooperação "está presidida por un criterio intergubernamental, característico del individualismo internacional". ${ }^{3}$

O que se pretende, no presente artigo, é descrever os principais fatos e idéias que fomentam a busca da integração latino-americana por todo o século XIX e que ainda inspiram essa busca em pleno século XXI.

\section{O pensamento de Simón Bolívar}

A Carta da Jamaica ${ }^{4}$, também designada como a Carta Profética, foi escrita em 6 de setembro de 1815 por Simón Bolívar e é um dos primeiros manuscritos a delimitar o pensamento da integração das colônias latino-americanas, naquele momento em luta pela independência em relação a Espanha. Apesar de Bolívar acreditar na ideologia liberal (no campo político e econômico) e no federalismo, considerava tais idéias de difícil aplicação nos países latino-americanos, diante da necessidade do estabelecimento de um governo forte e com poderes extraordinários para

\footnotetext{
${ }^{2}$ Azevedo, 1991, p. 73.

${ }^{3}$ Instituto Interamericano de Estudios Jurídicos Internacionales, 1969, p. 5.

${ }^{4}$ A carta da Jamaica tem esse nome em virtude de ter sido escrita por Bolívar enquanto encontrava-se exilado no território jamaicano, após a derrota dos revolucionários na tentativa de independência de 1810 e de 1813.
} 
assegurar a independência das antigas colônias em relação às metrópoles. Admirador do modelo político norte-americano ${ }^{5}$, Bolívar questionava, entretanto, a adoção do federalismo pelos Estados latino-americanos temendo um enfraquecimento da integração nacional diante da força das unidades federais. Para Panebianco, Bolívar crê em um

[...] modelo original do federalismo atenuado e adaptado às situações dos diversos países latino-americanos. Bolívar não crê no federalismo como modelo superior ao do Estado nacional centralizado, mas crê no federalismo compensador de um poder nacional forte e enérgico; não crê na soberania federal concorrente com a nacional, mas é paladino da integração dos Estados nacionais em mais vastas unidades. ${ }^{6}$

Bolívar vislumbrava inicialmente a constituição de um Estado republicano e democrático a partir da independência do Vice-Reinado de Nova Granada ${ }^{7}$, que futuramente deveria se integrar com os demais Estados latino-americanos. O poder desse novo Estado (Grã-Colômbia) deveria ser composto por um Poder Executivo eleito, vitalício e não-hereditário; uma Câmara ou Senado legislativo hereditário, com similitude a Câmara dos Lordes, na Inglaterra; e um corpo legislativo eleito com as mesmas atribuições da Câmara dos Comuns. ${ }^{8} \mathrm{O}$ modelo de poder espelhado no Reino Unido visava também atrair os ingleses para o projeto de financiamento da guerra de independência dos países latino-americanos, evitando uma tentativa de recolonização pelas metrópoles. Tomava tal possibilidade de aliança com o Reino Unido diante da resistência inglesa de aderir a Santa Aliança9

Entre a torrente de idéias que emana da Carta da Jamaica encontra-se uma das diretrizes que deveriam nortear, em 1826, o Congresso do Panamá: a união das facções, partidos e povos americanos para constituir governos livres e Estados independentes, bem como para lutar contra os inimigos comuns. A união entre os

\footnotetext{
${ }^{5}$ Bolívar visitou os Estados Unidos da América em 1807.

${ }^{6}$ Panebianco, 1981, p. 58-59.

${ }^{7}$ Constituído pela Colômbia, Venezuela, Panamá e parte do Equador.

${ }^{8}$ Belloto, 1983, p. 74.

${ }^{9}$ A Santa Aliança era constituída por França, Rússia, Prússia e Império Austro-Húngaro. Foi proposta pelo Czar da Rússia Alexandre I com a finalidade de governar os Estados de acordo com a justiça, caridade e paz cristã e, ao mesmo tempo, propagar a fé cristã. Fundamentava-se nas idéias adotadas no Protocolo de Troppau, pactuado pela Rússia e Império Austro-Húngaro em 1820. A Santa Aliança interviria para suprimir as revoluções liberais em qualquer parte do território europeu. Considerava as colônias americanas como mera extensão do território das metrópoles européias. Na prática visava à manutenção do status quo político da Europa, estabelecido no Congresso de Viena, mantendo a monarquia absoluta como modelo de governo. A Santa Aliança também projetou a Rússia como principal potência militar do continente europeu após o período napoleônico.
} 
Estados deveria ocorrer como produto de ações concretas e esforços dirigidos por todos os setores das sociedades (fatores internos) voltados para a obtenção e manutenção da independência, assim como pelo fato de a América Latina encontrarse órfã, ou seja, abandonada pelas nações européias (fatores externos), restandolhe, dessa forma, o caminho da convergência por meio dos processos integrativos como meio de sustentar a liberdade.

A Carta de Jamaica não pregava a necessidade do estabelecimento de uma única unidade político-institucional da América Latina, mas indicava que a agregação dos diversos Estados independentes, por meio de processos integrativos, seria o único caminho para obter e sustentar a liberdade advinda da independência.

A forma como se daria a agregação dos Estados da América Latina foi apresentada por Bolívar, conforme Vila, nas correspondências enviadas, posteriormente, aos governos da Grã-Colômbia ${ }^{10}$, do México, das Províncias Unidas do Rio da Prata $^{11}$, do Chile e da Federação Centro-Americana ${ }^{12}$, em 7 de dezembro de 1824, em que convidava esses países a participar do Congresso do Panamá. Bolívar também apresentou sua proposta na carta enviada ao vice-presidente da Colômbia General Santander, em 6 de janeiro e em 28 de junho de 1825, e no ensaio Um pensamento sobre o Congresso do Panamá, escrito em $1826 .{ }^{13}$ A estrutura institucional dessa imaginada e pretendida integração, segundo Aguirre, encontrava-se assentada sobre um modelo confederativo. Seria composta por uma Assembléia dos representantes das Repúblicas (Dieta), com sede no istmo do Panamá, cujos poderes gerais seriam: a) funcionar como um órgão de consulta entre os Estados-membros para definição de uma política externa comum, principalmente no que tange a assegurar a manutenção da independência dos países da América Latina; b) atuar como instituição responsável em promover a interpretação e aplicação dos tratados pactuados entre os Estados-membros, evitando ou dirimindo os conflitos entre esses Estados por meio da conciliação ou da arbitragem; e c) criar, administrar e controlar uma força armada confederada (marinha e exército). ${ }^{14}$

Bolívar pretendia a formação dessa Confederação com a participação de algumas das ex-colônias espanholas, bem como, de acordo com Donghi, com a asso-

\footnotetext{
${ }^{10}$ Constituída por Nova Granada (Colômbia), Venezuela, Panamá e parte do Equador.

${ }^{11}$ As Províncias Unidas do Rio da Prata eram constituídas pela Argentina e Uruguai. O Uruguai era, entretanto, disputado como parte do Império do Brasil (Província Cisplatina), tendo conquistado sua independência em 1828 .

${ }^{12}$ Os Estados Unidos da América Central, depois designados (1824) como Federação Centro-Americana, eram constituídos por Guatemala, Honduras, Nicarágua, El Salvador e Costa Rica, existindo como Estado até 1840.

${ }^{13}$ Vila, 1976, p. 177-198.

${ }^{14}$ Aguirre, 1983, p. 339.
} 
ciação do Reino Unido. ${ }^{15}$ Para atraí-la, acenava com a instituição de uma zona de livre comércio entre os Estados-membros, cujo principal beneficiário seria a Inglaterra. Em troca, o Reino Unido traria a segurança internacional que tal adesão representaria para a independência e soberania dos nascentes Estados, em contraposição a Santa Aliança e, mais tarde, a Doutrina Monroe ${ }^{16}$.

Bolívar idealizava uma Comunidade de Estados embasada em normas comuns e universais, devidamente codificadas, e que deveriam garantir a aplicação dos princípios da liberdade, da autodeterminação dos povos, da igualdade, do equilíbrio dos Estados e do poder de inserção dessa Comunidade nas decisões da Sociedade Internacional.

Ao mesmo tempo em que idealizava a aproximação dos Estados latino-americanos numa Confederação, Bolívar reconhecia as dificuldades dessa integração política. Entre os obstáculos à constituição da Confederação destacava-se a presença da estrutura federativa de alguns Estados, pelo fato de propiciar e reforçar a existência de lideranças locais fortes (caudilhismo regional) em detrimento dos poderes centrais constituídos, além do perigo, sempre presente, de uma tentativa de recolonização pela Espanha, apoiada pela Santa Aliança. Tais aspectos levaram Bolívar a admitir que a Confederação preconizada por ele já seria vitoriosa se conseguisse conservar-se por pelo menos dez ou doze anos.

Entre as propostas estabelecidas por Bolívar como meios de garantir a independência dos jovens Estados latino-americanos encontram-se as de fusão de Estados para a constituição de unidades com maior território e população, bem como o estabelecimento de um protetorado disfarçado, que deveria ser exercido pela Inglaterra. Quando da convocação para a realização de um Congresso no Panamá imaginou uma estrutura institucional que integrasse algumas das antigas colônias espanholas, agora independentes, sob a tutela garantidora inglesa.

Bolívar, por motivos diversos, não desejava a participação do Brasil e dos Estados Unidos, bem como das Províncias Unidas do Rio da Prata na Confederação proposta.

Para Bolívar, o Brasil não deveria participar por dois motivos: idealizava uma Confederação que reunisse tão somente as antigas colônias espanholas na América

\footnotetext{
${ }^{15}$ Donghi, 1985, p. 216.

${ }^{16}$ A Doutrina Monroe foi estabelecida na mensagem do presidente James Monroe ao Congresso norte-americano em 2 de dezembro de 1823. Estabelecia que o continente americano não seria objeto de recolonização após à independência dos Estados e advertia que qualquer intervenção das potências européias na América para reinstalar seu sistema político nas antigas colônias seria considerado uma ameaça à segurança dos Estados Unidos. A Doutrina também possuía um conteúdo intervencionista, ao estabelecer que qualquer política externa dirigida ao continente americano dependia da anuência dos Estados Unidos para sua efetivação.
} 
e vislumbrava no Brasil uma ameaça a ser neutralizada, já que o país era tido como o representante dos interesses da Santa Aliança na América. ${ }^{17}$ No que tange aos Estados Unidos, acreditava que a Doutrina Monroe tinha o mesmo conteúdo intervencionista do tratado constitutivo da Santa Aliança, além de não ter sido uma antiga colônia espanhola, gerando dificuldades lingüísticas e culturais insuperáveis. Por fim, não desejava a participação das Províncias Unidas do Rio da Prata em razão do alto grau de anarquia produzido pelas disputas internas naquele país (Federalistas e Unitários), bem como no Chile, e por ser o governo do Rio da Prata contrário à constituição de uma Confederação composta pelas antigas colônias espanholas na América, temendo o surgimento de um poder superior ao dos Estados recém-independentes. Conforme Cervo, as Províncias Unidas do Rio da Prata obtiveram sua independência da Espanha em 1816 sem conseguir, entretanto, manter as mesmas dimensões territoriais do antigo Vice-Reinado do Rio da Prata, já que, paulatinamente, Paraguai, Bolívia e Uruguai foram se tornando independentes. ${ }^{18}$

Apesar das ressalvas de Bolívar, o presidente da Grã-Colômbia, general Santander, que, como Chefe de Estado, era o responsável pelas gestões diplomáticas necessárias à realização do Congresso do Panamá, convidou o Brasil e os Estados Unidos a enviar representantes. As Províncias Unidas do Rio da Prata já haviam sido convidadas, anteriormente, pelo próprio Bolívar.

Santander, diferentemente de Bolívar, era contrário à formação de qualquer organização capaz de se antagonizar as forças regionais que estavam empenhadas em acelerar o processo de multiplicação das nacionalidades na América. Sem meios para opor-se abertamente ao Congresso do Panamá, optou por convertê-lo numa reunião de todos os países do hemisfério, independentemente das inclinações políticas, econômicas e sociais de cada país. Entendia que a multiplicidade de tendências reunidas evitaria a formação de qualquer Confederação com poderes suficientes para englobar as nascentes nacionalidades americanas, destacando a importância dos fatores regionalistas em detrimento da união.

\section{O Congresso do Panamá}

Em 13 de junho de 1825, quase um ano antes da abertura do Congresso, portanto, chegaram ao Panamá os representantes do Peru. Em 18 de março de 1826 chegaram os representantes da Federação Centro-Americana, seguidos pelos

\footnotetext{
${ }^{17}$ Em razão de o Brasil ter adotado a forma de governo monárquica e pelo fato de possuir uma casa imperial reinante aparentada com certas monarquias européias que compunham a Santa Aliança (Habsburgos e Bourbons).

${ }^{18}$ Cervo, 1998, p. 82-87.
} 
representantes do México, em 4 de junho. A essas delegações juntaram-se as da Grã-Colômbia, como Estado organizador, e os observadores enviados pelo Reino Unido e pelo Reino dos Países-Baixos ${ }^{19}$.

As Províncias Unidas do Rio da Prata declinaram do convite de participação no Congresso do Panamá temendo que as propostas da Grã-Colômbia acabassem por predominar nas decisões a ser tomadas. Além do mais, desconfiavam das idéias de Bolívar, que buscava convencer o Reino Unido a salvaguardar a independência dos novos Estados. ${ }^{20}$

Os Estados Unidos condicionaram o envio de representante à aprovação, pelo Congresso norte-americano, das verbas necessárias às despesas de seus delegados. O governo norte-americano também declarava não ser favorável à formação de uma estrutura institucional com poderes de decidir, em última instância, as controvérsias entre os Estados americanos ou, ainda, de pretender regular, de um modo qualquer, a conduta desses por meio de normas legisladas. Por fim, os Estados Unidos acabaram credenciando seu representante diplomático em Bogotá como delegado junto ao Congresso do Panamá. Ocorre que o sr. Anderson faleceu antes da abertura do Congresso, o que levou os Estados Unidos a não participar dos trabalhos.

O Império do Brasil aceitou o convite para participar do Congresso, mas seu representante não chegou a tempo de acompanhar as discussões e deliberações. ${ }^{21}$

O Chile não mandou representante em razão da guerra civil estabelecida entre liberais e conservadores, em disputa pelo governo. ${ }^{22} \mathrm{~A}$ Bolívia também não pôde enviar o seu representante.

A instalação do Congresso do Panamá ocorreu em 22 de junho de 1826 e foi precedida de negociações prévias que demonstraram a resistência de algumas delegações em estabelecer a liberdade de comércio entre os países, além da ferrenha oposição da delegação peruana em consagrar a adoção dos princípios democráticos e republicanos que serviriam de natural contraposição aos princípios monárquicos e absolutistas da Santa Aliança. O Congresso findou em 15 de julho de 1826.

Entre as principais conquistas do Congresso do Panamá, estabelecidas com a celebração do Tratado de União, Liga e Confederação Perpétua pactuado entre os

\footnotetext{
${ }^{19}$ Constituído por Holanda e Bélgica.

${ }^{20}$ Em 1806 e em 1807, a Inglaterra enviou uma Armada com tropas para realizar a ocupação e conquista de Buenos Aires. Nessa época a Argentina ainda integrava o Vice-Reinado do Rio da Prata como colônia da Espanha. A população de Buenos Aires impediu a transferência de poder aos ingleses, frustrando as duas tentativas de ocupação.

${ }^{21}$ Cervo; Bueno, 1992, p. 41.

${ }^{22}$ A luta armada entre conservadores e liberais, no Chile, perdurou de 1823 a 1830.
} 
participantes, encontram-se: a) a doutrina do caráter permanente da Assembléia da Liga, que deveria permanecer reunida na sua sede; b) a autonomia para tomar decisões nas competências que lhe eram próprias; c) a jurisdição soberana sobre $o$ território que lhe serviria de sede permanente; d) a divisão dos encargos de constituição do exército e da marinha confederados, estabelecidos de acordo com a população de cada Estado-membro; e e) o reconhecimento a autodeterminação dos povos latino-americanos e o reconhecimento dos direitos dos indivíduos. ${ }^{23}$

Para sede permanente da Assembléia da Confederação foi escolhida a cidade de Tacubaya, no México.

O Tratado de União, Liga e Confederação Perpétua pactuado não avançou no sentido do estabelecimento da união política dos Estados (idéias bolivarianas), mas meramente na fixação de mecanismos de cooperação entre os seus membros. Entretanto, o tex to do Tratado continha idéias tidas como precursoras da integração latino-americana, dentre elas a indicação da forma de governo dos Estados-membros (republicana e democrática), princípios gerais de convivência pacífica entre os povos e respeito ao direito internacional.

O artigo primeiro do Tratado estabelecia a criação de um exército composto de 60 mil homens, cabendo a Colômbia recrutar 15.250, a Federação Centro-Americana 6.750, ao Peru 5.250 e ao México 32.750. Já os artigos $15^{\circ}$ e $16^{\circ}$ estabeleciam a criação de uma marinha composta por 22 vasos-de-guerra, bem como a divisão e responsabilidade pelo aparelhamento das naus entre os países pactuantes. Ocorre que tal aparato militar, longe de ser mantido e administrado pela Assembléia da liga, como era o ideal de Bolívar, deveria ser constituído e administrado pelos Estados-membros, caracterizando-se como meras disposições de defesa e assistência recíproca.

Para as delegações presentes no Panamá a existência de um corpo militar próprio e dependente da Liga daria margem a que, no futuro, ocorresse a formação de uma estrutura política e militar continental superior a dos Estados, ameaçando a independência desses. Além do mais, os Estados participantes já possuíam lideranças locais (caudilhos) e temiam que a Liga pudesse gerar uma centralização de poder que destruísse tais lideranças.

O tratado também estabelecia a finalidade da Liga na defesa dos princípios democráticos e republicanos, salvaguardando, entretanto, no artigo $29^{\circ}$, a não-exclusão de qualquer membro que variasse ou diferisse sua forma de governo da defendida pela Liga, a não ser pelo voto unânime de todas as partes constitutivas.

\footnotetext{
${ }^{23}$ Instituto Interamericano de Estudios Jurídicos Internacionales, 1969, p. 428-430.
} 
No que tange à adoção de uma política externa comum e a criação de um conjunto de normas jurídicas aplicáveis aos países americanos, em substituição às normas clássicas do direito internacional cristão-europeu, as negociações resultaram infrutíferas, deixando o acordo de conter quaisquer disposições a este respeito. Os Estados, contudo, concordaram no estabelecimento da obrigação de buscar a resolução pacífica dos conflitos, o reconhecimento da competência jurisdicional da Assembléia da Liga em caso de conflitos entre os Estadosmembros e na abolição da escravatura.

O tratado não contemplava as principais idéias do Libertador, mas continha alguns elementos para a formação de um processo de integração, como o estabelecimento de uma Assembléia de plenipotenciários com caráter permanente.

O Congresso do Panamá encerrou-se em 15 de julho de 1826.

Quando Bolívar tomou conhecimento do teor do tratado manifestou seu desagrado em relação aos poucos poderes outorgados à Assembléia da Confederação, afirmando que os mesmos seriam por demais tênues, sem força para impor suas decisões. O Libertador entendia que o tratado firmado no Panamá não dispunha da eficácia necessária para impedir as tendências separatistas, sendo, dessa forma, uma vitória dos interesses regionais e nacionais sobre os interesses comunitários.

A Inglaterra não via qualquer vantagem na criação de uma Confederação de Estados latino-americanos, uma vez que lhe era mais fácil negociar tratados vantajosos junto a cada um dos Estados (fragmentados e fracos) do que reunidos em conjunto. Também temia que uma Confederação latino-americana acabasse sofrendo maior influência dos Estados Unidos (Doutrina Monroe), dificultando seus interesses econômicos na região. ${ }^{24}$

O Tratado de União, Liga e Confederação Perpétua foi ratificado somente pelo governo da Grã-Colômbia, não tendo entrado em vigor.

\section{Os congressos posteriores}

Após o final do Congresso do Panamá, alguns delegados se dirigiram para a sede permanente da Confederação, Tabucaya, visando efetivar o dispositivo que reconhecia o caráter permanente da Assembléia. Pouco tempo depois retornaram a seus Estados, quando se constatou que a Assembléia não se reuniria pela ausência de muitos plenipotenciários.

\footnotetext{
${ }^{24}$ Cervo; Bueno, 1992, p. 38.
} 
Em 1831, 1838, 1839 e 1840, o México dirigiu convocação formal aos demais membros do tratado e a outras nações latino-americanas, para participar de novas conferências com o intuito de continuar os trabalhos iniciados no Congresso do Panamá, mas elas acabaram não se realizando pela ausência de interessados.

No período de 11 de dezembro de 1847 a $1^{\circ}$ de março de 1848 reuniram-se em Lima os representantes de Bolívia, Chile, Colômbia, Equador e Peru, visando dar seguimento aos ideais lançados pelo Libertador. ${ }^{25}$ Neste Primeiro Congresso de Lima são assinados tratados referentes a: 1) convenção consular; 2) convenção de correios; 3) novo tratado de União e Confederação; e 4) tratado de comércio e navegação. Mais uma vez, nenhum dos tratados celebrados foi ratificado.

A realização e o resultado do Primeiro Congresso de Lima demonstraram claramente que 21 anos após o Congresso do Panamá, as idéias de Bolívar ainda direcionavam as experiências integracionistas na América Latina. Outra constatação era de que a Confederação de países latino-americanos não se materializaria somente com a criação de uma estrutura política mas, principalmente, por meio da aproximação dos Estados em diversas áreas de interesses comuns, como o comércio e a defesa.

Sob a égide dessa constatação realizou-se em 1856, no Chile, com a participação do Estado-sede mais as do Equador e do Peru, novo Congresso que culminou, em 15 de setembro de 1856, com a assinatura do Tratado Continental de Aliança e Assistência Recíproca, de índole semelhante à do Primeiro Congresso de Lima.

Os congressos de Lima e de Santiago foram influenciados também pelas idéias de Andrés Bello. Para Bello, segundo Panebianco, os Estados participantes deveriam atribuir certa dose de soberania aos congressos para legislar sobre um direito internacional americano que deveria ser aplicado pelos Estados participantes com a assinatura dos plenipotenciários e independentemente da ratificação dos tratados. ${ }^{26}$ Dessa forma Bello vislumbrava os congressos como órgãos intergovernamentais e supranacionais.

Ainda em 1856, em 9 de novembro, foi assinado em Washington, por oito países americanos, o Tratado de Aliança e Confederação, análogo ao do Congresso de Santiago. ${ }^{27}$ Um dos motivos que impulsionaram a convocação do Congresso de Washington foi à presença de flibusteiros, principalmente americanos, nos mares do

\footnotetext{
${ }^{25}$ Instituto Interamericano de Estudios Jurídicos Internacionales, 1969, p. 430.

${ }^{26}$ Panebianco, 1991, p. 61-62.

${ }^{27}$ Participaram e subscreveram os tratados os representantes dos Estados Unidos, Costa Rica, México, Colômbia, Peru, El Salvador, Venezuela e Guatemala.
} 
Caribe e a invasão da Nicarágua por um deles (William Walker ${ }^{28}$ ). ${ }^{29} \mathrm{O}$ Tratado preconizava a assistência defensiva mútua entre os Estados em caso de ataques externos e internos (nos casos de expedições de exilados que buscassem derrubar qualquer dos governos aliados). Também estava prevista a convocação dos plenipotenciários latino-americanos em Lima, em 1857, para dar seqüência a idéia do estabelecimento de uma confederação latino-americana, reunião essa que não ocorreu.

Tanto no primeiro Congresso de Lima quanto no de Washington nenhum dos tratados foi ratificado. ${ }^{30}$

Entre 15 de dezembro de 1864 e em 12 de março de 1865 reuniram-se em Lima os representantes do Peru, Bolívia, Chile, Equador, Venezuela, Colômbia, El Salvador e Argentina para a realização de novo Congresso. No referido Congresso foram acordados tratados relativos: a) à circulação de correios; b) ao comércio e à livre navegação; c) à conservação da paz e solução pacífica dos conflitos; e d) à união dos Estados e o estabelecimento de aliança defensiva.

Diferentemente dos congressos anteriores, o segundo Congresso de Lima reuniu-se em virtude da crescente intervenção européia nas questões internas e externas dos Estados latino-americanos. ${ }^{31}$ Suas decisões abandonaram a linha confederativa adotada por Bolívar para centrar-se num estreitamento de laços intergovernamentais, buscando a cooperação internacional e a junção de esforços para o enfrentamento de problemas comuns.

\footnotetext{
${ }^{28}$ William Walker foi contratado para chefiar uma pequena tropa de mercenários americanos que deveriam colaborar para a deposição do governo constituído da Nicarágua, ajudando os "democratas" nicaragüenses a tomar o poder. Diante da guerra civil existente na Nicarágua, Walker optou por atribuir-se o título de Presidente do país logo após ter tomado Granada, capital do governo legalista. Seu governo foi reconhecido por um curto período pelo governo norte-americano, que tinha interesse no território nicaragüense, já que o transporte comercial entre a costa leste e costa oeste americanas tinha sua rota principal passando pelo território e portos da Nicarágua. Também os primeiros estudos para a construção de um canal inter-oceânico ligando o Atlântico ao Pacífico foram feitos para a sua realização em território da Nicarágua. Durante o período de Walker na presidência da Nicarágua foi revogada a lei que proibia a escravidão no país. Walker foi deposto por um exército combinado de países centro-americanos.

${ }^{29}$ Aquino; Lopes; Lemos, 1981, p. 127.

${ }^{30}$ Instituto Interamericano de Estudios Jurídicos Internacionales, 1969, p. 431.

${ }^{31}$ Por exemplo: em 1861 a Espanha retomou e estabeleceu um protetorado na República Dominicana; em 1861-1862, tropas combinadas da Espanha, Inglaterra e França invadiram o território mexicano para impor o pagamento das dívidas e indenizações devidas aos cidadãos desses países; em 1864 a Espanha enviou uma armada que ocupou a ilha Chincha (região de guano), pertencente ao Peru, além de bombardear, em 1866, os portos de Valparaíso (Chile) e Callao (Peru), antes de retornar a Europa.
} 
Para Panebianco, tanto o primeiro quanto o segundo Congresso de Lima estão impregnados das idéias do argentino Alberdi, ao privilegiar a regulamentação, através de legislação internacional uniforme, de um conjunto amplo de problemas comuns como o comércio, os transportes, as comunicações, a defesa e o asilo político. Dessa forma os congressos não teriam mais uma função primordialmente antieuropéia, mas a de promover a colaboração dos Estados para as questões econômicas e sociais comuns. Essa orientação passaria a prevalecer, daí por diante, nos congressos panamericanos. ${ }^{32}$

Independentemente das aludidas mudanças de rumos, nenhum dos tratados foi ratificado.

Apesar do caráter sub-regional, menção deve ser feita aos esforços de integração desenvolvidos em 1867 entre Bolívia, Peru, Chile e Equador, realizados pelo chanceler do Peru dom José Antonio Barrenechea, por sugestão do chanceler do Chile, dom Marcial Martinez. As principais medidas discutidas eram: a) a criação de uma cidadania comum voluntária; b) o estabelecimento de uma diplomacia comum; c) a simetria das moedas e a criação de uma moeda comum; d) o estabelecimento de listas comuns para a livre importação de artigos; e) a reunião anual de uma Assembléia de plenipotenciários; f) a uniformização das legislações; g) o estabelecimento de estradas, correios e telégrafos comuns; h) o estabelecimento de uma política comum de imigração para atrair mão-de-obra qualificada; e i) o estabelecimento de uma nomenclatura comum para os produtos de livre circulação. ${ }^{33}$

Firmaram-se alguns instrumentos internacionais, como o Tratado Tripartite entre Bolívia, Peru e Chile sobre princípios de direito internacional e o Tratado de Amizade, Comércio e Navegação entre Chile e Peru, com o intuito da concretizar as medidas discutidas. Entretanto, o projeto de integração deixou de existir quando o Chile, a Bolívia e o Peru, após um estremecimento de suas relações diplomáticas, entraram em guerra

\footnotetext{
32 Panebianco, 1991, p. 62-63.

${ }^{33}$ Basadre, 1961, p. 1672-1673.

${ }^{34}$ Trata-se da Guerra do Pacífico, ocorrida entre 1879 e 1883, em que Bolívia e Peru eram aliados contra o Chile. O Chile foi vitorioso na guerra, anexando ao seu território o único território boliviano com saída para o mar (Antofagasta), mais a província de Tarapacá e parte da província de Arica, no Peru. O motivo da disputa foi a imposição, pelo governo boliviano, de um imposto sobre o guano produzido na região boliviana de Antofagasta. Como a produção de guano na região era dominada por chilenos, com apoio do capital inglês, instaurou-se uma revolta contra o governo boliviano, com o apoio do Chile e que gerou o confronto armado entre os Estados. A Bolívia recebeu o apoio do Peru. ${ }^{35}$ Trata-se do conflito contra a Espanha entre 1865 e 1868, onde Chile, Peru, Bolívia e Equador confrontaram uma esquadra enviada pela Espanha para cobrar dívidas contraídas no processo de reconhecimento da independência desses países latino-americanos. A esquadra espanhola ocupou inicialmente a ilha Chincha, no Peru, e posteriormente bombardeou o porto de Valparaíso (Chile), além de tentar realizar o bloqueio do porto de Callao (Peru). A esquadra espanhola retirou-se após ter sido confrontada com a esquadra combinada do Peru e do Chile durante o bloqueio de Callao.
} 
pelas regiões de produção de guano (principal adubo da época). ${ }^{34}$ Curiosamente, fora uma guerra que provocara a aproximação anterior desses países. ${ }^{35}$

Menção também deve ser feita à tentativa de recriar uma unidade política integrada na América Central, entre 1896 a 1898 - a então designada República da América Central, com a participação de Honduras, El Salvador e Nicarágua. A referida tentativa se juntou a outras anteriores nos anos de 1846, 1847, 1849, 1850, 1856, 1876 e 1885, todas posteriores à dissolução da Federação Centro-Americana em 1840. Para Escudero, a dissolução de Federação Centro-Americana ocorreu principalmente pelo predomínio político e econômico da Guatemala sobre as demais regiões, pela debilidade do governo central em relação ao governo dos Estados federados, pela existência de poucas vias de comunicação entre os Estados federados e pelas disputas políticas entre conservadores e liberais. ${ }^{36}$ Após todas essas tentativas listadas, o modelo de integração entre os Estados da América Central passou a ser o da aproximação gradual, visando o estabelecimento de uma política externa de cooperação para satisfação de certos interesses comuns, deixando-se de lado a criação de uma unidade política federada ou confederada. Também na América Central, a política externa em relação aos demais países latino-americanos cedeu lugar a uma conduta mais pragmática de colaboração designada como Panamericanismo.

\section{$4 \quad$ O panamericanismo}

O Panamericanismo pode ser definido como o movimento dos países americanos para criar e fomentar a colaboração entre os Estados em diversos âmbitos de interesses comuns, sejam militares, econômicos, políticos, diplomáticos, sociais ou culturais.

Cessada a possibilidade de recolonização dos Estados latino-americanos e diminuído o perigo de intervenção por parte das potências européias ${ }^{37}$, começam a declinar as idéias próprias do "Confederalismo Bolivariano", com ênfase numa integração política dos Estados, sendo substituída por um conjunto de ideais mais pragmáticos centrado numa política de aproximação gradual e de colaboração entre os Estados para a materialização de certos objetivos comuns.

As relações entre os países latino-americanos não mais deverão se assentar sob um idealismo confederacionista com Estados politicamente unidos, mas sob a

\footnotetext{
${ }^{36}$ Escudero, 1969, p. 07.

${ }^{37}$ É preciso recordar, entretanto, que em 1902 uma esquadra italiana, inglesa e alemã promoveu o bloqueio e atacou os principais portos da Venezuela em razão da cobrança de dívidas dos cidadãos desses Estados contra o governo venezuelano.
} 
égide da colaboração das unidades estatais para a concretização dos interesses individuais de cada uma. O projeto de união política cede lugar à sedimentação das relações intergovernamentais de colaboração, sem vinculação à questão de perda da soberania provocada pela adesão a um ente confederativo, e voltada para a consecução dos objetivos individuais (nacionais).

Manifestação desse novo rumo é a primeira Conferência Internacional Americana, realizada em Washington entre os 2 de outubro de 1889 e 19 de abril de 1890.

Segundo o Instituto Interamericano de Estudos Jurídicos Internacionais, na Conferência de Washington foi a precursora da Organização dos Estados Americanos (OEA) e da sua Secretaria Geral:

En esta reunión, a la cual concurrieron delegaciones de todas las repúblicas entonces existentes en América, con excepción de la República Dominicana, nace el Sistema Interamericano y con él la primera expresión de la moderna organización internacional regional. En efecto, por resolución adoptada en la Conferencia el 14 de abril de 1890, se creó la 'Unión Internacional de las Repúblicas Americanas', teniendo como órgano permanente la 'Oficina Comercial de las Repúblicas Americanas' $[\ldots] . .^{38}$

Durante a realização da Conferência foi discutida a proposta de estabelecimento de uma união aduaneira entre os Estados Americanos. ${ }^{39}$ A proposta foi descartada dadas as dificuldades decorrentes das questões relativas à soberania estatal, bem como de adequação da ordem jurídico-institucional das Constituições. As dificuldades foram classificadas como insuperáveis para a organização de semelhante estruturação do comércio regional. No mesmo sentido foram rechaçadas as propostas de formulação de tratados regionais estabelecendo um mesmo território aduaneiro entre várias nações, sob o manto de reciprocidade.

Os Estados participantes optaram por uma recomendação para a celebração de tratados bilaterais e plurilaterais, de reciprocidades parciais, de acordo com a conveniência e interesse de cada Estado, dentro dos seus objetivos nacionais.

Foi criado o Escritório Comercial das Repúblicas Americanas em Washington, como pólo aglutinador do estreitamento dos laços políticos, econômicos e culturais dos países americanos.

Entre as matérias objeto de propostas e recomendações encontram-se: a) a adoção de uma nomenclatura aduaneira uniforme, bem como de processos adua-

\footnotetext{
${ }^{38}$ Instituto Interamericano de Estudios Jurídicos Internacionales, 1969, p. 433-434.

${ }^{39}$ Inspirados pelo sucesso da união aduaneira dos Estados Alemães, que facilitou o surgimento do Império Alemão.
} 
neiros comuns e direitos portuários homogêneos; b) a exploração e construção de uma estrada de ferro interamericana; c) o estabelecimento de uma união monetária internacional americana; e d) a livre navegação dos rios internacionais para as nações ribeirinhas.

Foi pactuado um tratado estabelecendo a obrigação dos Estados de solucionar seus litígios comuns por meios pacíficos, especialmente através da arbitragem. O aludido tratado não entrou em vigor por falta de ratificações necessárias.

As conferências que se seguiram à primeira Conferência procuraram aperfeiçoar as modalidades de cooperação dos Estados participantes, assim como estabelecer mecanismos econômicos que facilitassem o intercâmbio comercial. Foram elas: a) a Conferência do México, em 1901; b) a Conferência do Rio de Janeiro, em 1903; c) a Conferência de Buenos Aires, em 1910; d) a Conferência de Santiago, em 1923; e) a Conferência de Havana, em 1928; f) a Conferência de Montevidéu, em 1933; g) a Conferência de Lima, em 1938; h) a Conferência de Bogotá, em $1948^{40}$; e i) a Conferência de Caracas, em 1954.

As conferências panamericanas se caracterizaram como um esforço diplomático dos Estados no sentido de estabelecer mecanismos de aproximação entre si. Como desde a realização da primeira Conferência verificaram-se inúmeras dificuldades para o estabelecimento de uma zona de livre comércio ou de uma união aduaneira no continente, a opção foi pelo estabelecimento de conferências periódicas que permitissem a pactuação de tratados bilaterais ou multilaterais entre os Estados americanos, visando uma maior aproximação e convergência em assuntos comuns. As propostas iam desde a criação de um Banco Panamericano ${ }^{41}$ até a criação de uma legislação aduaneira comum; estradas-de-ferro e sistemas de comunicação interamericanos, entre outras.

Durante este período, os países latino-americanos não se mais se dispunham a uma integração de qualquer ordem (política, econômica, cultural, militar). Encaravam a aproximação aos demais países da região como uma opção de suas políticas externas, sujeitas às variações políticas resultantes dos grupos e idéias que detivessem o poder em cada Estado. A referida perspectiva só vai ser modificada a partir das dificuldades econômicas dos Estados latino-americanos após a

\footnotetext{
${ }^{40} \mathrm{Na}$ Conferência de Bogotá, em 1948, foi criada a Organização dos Estados Americanos (OEA), organização internacional regional fundamentada na solidariedade dos Estados do Continente Americano.

${ }^{41}$ Atualmente têm-se o Banco Interamericano de Desenvolvimento (BID), criado em 1959, ou seja, quase 70 anos após a primeira Conferência Panamericana. A proposta de criação de um banco de fomento ao desenvolvimento latino-americano já havia sido feita por Alberdi, quando do primeiro Congresso de Lima, em 1846.
} 
II Guerra Mundial e aos esforços desenvolvidos pela CEPAL ${ }^{42}$ na década de 1950. Dessa nova visão - que contempla a necessidade do estabelecimento de laços mais fortes entre os Estados, o estabelecimento de instituições mais complexas com poder de decisão em matérias de competências concorrentes ou exclusivas que tenham sido delegadas pelos Estados e visando o cumprimento de metas econômicas comuns - se estruturaram, a partir da década de 1950, as modernas organizações internacionais de integração econômica: o Mercado Comum Centro-Americano, o Pacto Andino, a Associação Latino-Americana de Livre Comércio (ALALC), a Associação Latino-Americana de Desenvolvimento e Integração (ALADI) e o Mercosul.

\section{Conclusão}

A análise histórica da integração latino-americana no século XIX indica a prevalência do fator político como principal elemento do processo. Alguns pensadores acreditavam que a sobrevivência dos Estados latino-americanos após a independência só poderia ser mantida por meio do estabelecimento de laços políticos sólidos que levassem ao agrupamento dos Estados em entes federativos ou confederativos. Dessa forma, o motivo central da integração seria a possibilidade de manutenção da independência política conquistada contra a ameaça de uma recolonização pelos países europeus ou de intervenção, pelos Estados Unidos da América, em razão da Doutrina Monroe (fator externo). Outro motivo da integração política seria a possibilidade de criação e consolidação de uma nacionalidade latino-americana em virtude da proximidade dos laços culturais (língua, costumes, tradições trazidas da Espanha e de Portugal), bem como da possibilidade de implantação da forma republicana e democrática nos governos regionais.

O Brasil acabou ficando à margem das primeiras tentativas de integração por dois motivos centrais: a) adotou a forma de governo monárquica, diferenciados-se dos demais Estado latino-americanos, que adotaram a forma de governo republicana; ${ }^{43} \mathrm{e}$ b) não possuía as mesmas proximidades culturais dos demais Estados latinoamericanos em razão da colonização portuguesa.

Enquanto perdurou a ameaça de intervenção de países europeus ou dos Estados Unidos, os países latino-americanos buscaram a integração. Cessada tal ameaça e consolidadas as nacionalidades, passaram a não mais buscar qualquer aproxi-

\footnotetext{
${ }^{42}$ Comissão Econômica para a América Latina e o Caribe, criada em 1948, vinculada a Organização das Nações Unidas (ONU) e que têm entre suas atribuições a de promover o desenvolvimento econômico e social mediante a cooperação e a integração de caráter regional e sub-regional.
} 
mação que implicasse perda de soberania dos Estados para uma organização internacional, instaurando o período do panamericanismo.

Somente o surgimento de novas ameaças externas e internas de natureza econômica, como o subdesenvolvimento, a imposição de políticas econômicas e o controle do mercado pelos países ricos (europeus e os Estados Unidos), fez com que os países latino-americanos fossem novamente convencidos a buscar a construção de novos processos de integração, abandonando a conduta tímida e individualista da cooperação para buscar uma nova inserção no cenário internacional globalizado por meio dos blocos econômicos. ${ }^{44}$

Conclui-se, assim, que o processo de integração latino-americano foi e é motivado, principalmente. pelo temor decorrente das ameaças externas à independência dos Estados da região, seja em razão dos aspectos políticos (que predominaram no século XIX), seja em razão dos aspectos econômicos (que passaram a predominar a partir de 1950). Por outro lado se vislumbra, recentemente, uma nova perspectiva de integração que busca transformar o "inimigo" em aliado, como a negociação de uma zona de livre comércio entre Mercado Comum do Cone Sul (Mercosul) e União Européia ou, ainda, o estabelecimento da Associação de Livre Comércio das Américas (ALCA).

\section{Referências}

AGUIRRE, Indalecio Liévano. Bolivar. Madrid: Cultura Hispanica, 1983. AMORIM, Celso Luiz Nunes. O Mercado Comum do Sul e o contexto hemisférico. Série política internacional 4. São Paulo, jun., 1991. AQUINO, Rubim Santos Leão de; LOPES, Oscar G. P. C., LEMOS, Nivaldo Jesus F. de. História das sociedades americanas. Rio de Janeiro: Eu \& Você, 1981.

AZEVEDO, Araminta Mercadante de. Os aspectos institucionais da integração latino-americana. Revista de informação legislativa. v. 30, 1991.

BASADRE, Jorge. Historia de la República del Perú. Lima: Ricardo Palma, t. 4, 1961.

BELLOTTO, Manoel Lelo et al. Simon Bolivar. São Paulo: Ática, 1983.

\footnotetext{
${ }^{43} \mathrm{O}$ único Estado latino-americano que também adotou a monarquia foi o México, durante dois curtos períodos de tempo: a) após a independência, entre 1821 e 1823; e b) durante a ocupação francesa, entre 1864 e 1867.

${ }^{44}$ Nesse sentido: Gay, 1967, p.15-19; Amorim, 1991, p. 1-8.
} 
CERVO, Amado Luiz; BUENO, Clodoaldo. História da política exterior do Brasil. São Paulo: Ática, 1992.

CERVO, Amado Luiz; RAPOPORT, Mario (org.). História do cone sul. Brasília: Unb; Rio de Janeiro: Revan, 1998.

DONGHI, Tulio Halperín. História de América Latina 3. Madrid: Alianza, 1985.

ESCUDERO, Eduardo Vergara. Bases institucionales y jurídicas del mercado comum centroamericano. Santiago: Juridica, 1969.

GAY, Gaston de Prat. Política internacional del grupo latinoamericano.

Buenos Aires: Abeledo Perrot, 1967.

INSTITUTO INTERAMERICANO DE ESTUDIOS JURIDICOS

INTERNACIONALES. Derecho de la integrácion latinoamericana. Buenos Aires: De Palma, 1969.

PANEBIANCO, Massimo. In: LANDIM, José Francisco Paes (coord.). Direito e integração. Brasília: Unb, 1981.

VILA, Manuel Perez. Doctrina del libertador.Venezuela: Ayacucho, 1976. 